\title{
As contribuições do programa bolsa família sob a ótica das mulheres beneficiárias do assentamento Nova Descoberta, no Município de São Raimundo das Mangabeiras, e as dimensões de desenvolvimento de Amartya Sen
}

\author{
The contributions of Bolsa Familia's Program from the viewpoint of beneficiaries \\ women at Nova Descoberta settlement in São Raimundo das Mangabeiras \\ municipality and the development dimensions of Amartya Sen
}

1 Hortência de Sousa Viegas hortencia.viegas@ifma.edu.br
${ }_{2}$ Monica Franchi Carniello

\footnotetext{
1 Mestre em Gestão e Desenvolvimento Regional pela Universidade de Taubaté. Instituto Federal do Maranhão. Universidade de Taubaté.

2 Pós-doutorado em Comunicação (Universidade do Minho). Pós-doutorado em Comunicação (UMESP). Universidade de Taubaté. Faculdade de Tecnologia de Pindamonhangaba, FATEC
}

\section{Resumo}

Os programas de transferência de renda são frutos de políticas públicas que visam minimizar a desigualdade de oportunidades na sociedade, fundamentado na premissa de que, em uma sociedade desenvolvida os indivíduos possuem equidade no acesso a oportunidades, escolhas e direitos. 0 objetivo deste estudo é trazer a visão das beneficiárias do Programa Bolsa Família (PBF) que vivem no Assentamento Nova Descoberta, no município de São Raimundo das Mangabeiras - MA, e analisar, a partir das dimensões de desenvolvimento de Amartya Sen, suas condições de vida. Trata-se de uma pesquisa de campo, descritiva, qualitativa com aplicação de entrevista com as beneficiárias do Bolsa Família, baseada no conceito de desenvolvimento de Amartya Sen. A pesquisa foi aprovada por Comitê de Ética em Pesquisa (CAAE 09016319.8.0000.5501). Observou-se que as famílias do Assentamento Nova Descoberta atravessaram várias etapas de luta para conquistarem e permanecerem na terra. 0 assentamento possui hoje 15 famílias assentadas, e dessas, 5 recebem o Bolsa Família. Após o fim da adesão do Programa Nacional de Alimentação - localmente o convênio era celebrado com a Prefeitura de São Raimundo das Mangabeiras - o Programa Bolsa Família se tornou a principal renda fixa das beneficiárias e suas famílias, tendo ajudado na melhoria da qualidade de vida, pois foi através desse recurso que as beneficiárias puderam, inclusive, estruturar seus lares.

\section{Palavras-chave:}

Desenvolvimento humano. Políticas Públicas. Programa de Transferência de Renda.

\begin{abstract}
Programs related to income transfer are results of public policies aimed at minimizing inequality of opportunity in Brazilian society, based on the premise that in a developed society, people have equity to access opportunities, choices and rights. The objective of the study is to show a vision of Bolsa Familia's Program (PBF) beneficiaries who live in Nova Descoberta settlement in São Raimundo das Mangabeiras city - MA and to analyze from the development dimensions of Amartya Sen their living conditions. This is a field research, descriptive, qualitative, applying an interview to the Bolsa Familia's beneficiaries, based on Amartya Sen's concept of development. The project was approved by the Research Ethics Committee (CAAE 09016319.8.0000.5501). Noted that as the families at Nova Descoberta Settlement went through various stages of struggle to conquer and stay on land. Nowadays, the Community has 15 settled families, and 5 of these receive Bolsa Familia. After the end of the National Food Program membership - locally the agreement with São Raimundo das Mangabeiras Municipality - Bolsa Familia's Program has become the main fixed income to the beneficiaries and their families, the program has also helped in the improvement of the quality of life, because by using this resource the beneficiaries could even structure their lives.
\end{abstract}

\section{Keywords:}

Human development. Public policy. Income Transfer Program.

\section{Como você deve citar?}

VIEGAS, Hortência de Sousa; CARNIELLO, Monica Franchi. As contribuições do programa bolsa família sob a ótica das mulheres beneficiárias do assentamento Nova Descoberta, no Município de São Raimundo das Mangabeiras, e as dimensões de desenvolvimento de Amartya Sen. Cadernos UniFOA, Volta Redonda (RJ), v. 16, n. 47, p. 75 - 89, dez, 2021. 


\section{INTRODUÇÃO}

A realidade socioeconômica da sociedade brasileira tem a pobreza como fenômeno social, que coloca o país em evidência no cenário internacional, sobretudo pelos altos níveis de desigualdade de renda, particularmente nas regiões Norte e Nordeste. Assim, a busca por oferecer melhores condições de vida à população mais pobre sempre tem se revelado como um grande desafio a ser alcançado. "Desde a consolidação do PBF, instalou-se um amplo debate acerca de seu potencial para reduzir a pobreza e promover queda na desigualdade de renda existente no Brasil" (IPEA, 2010, p.08).

É a pobreza que tem evidenciado o Brasil como um país da desigualdade social. Esse fenômeno põe o país no centro de debates, principalmente no que se refere à exclusão social. Diversos países têm um sistema de proteção social, cujo objetivo é regular e minimizar essas diferenças, não sendo essa uma especificidade dos países considerados em desenvolvimento, uma vez que, mesmo países considerados desenvolvidos, possuem um sistema de proteção social com políticas públicas que visam superar as mazelas sociais.

O termo "pobreza" é frequentemente associado à carência ou à falta de acesso, por longos períodos, a recursos, bens e serviços essenciais à qualidade de vida. Diversas são as perspectivas sobre esse fenômeno. Tendo como ponto de partida a perspectiva da renda, a pobreza é definida como a simples falta de acesso à renda para consumo e, nesse caso, os pobres seriam aqueles com renda insuficiente para "satisfazer necessidades básicas definidas pela sociedade". No entanto há outros direitos e necessidades básicas que não dependem necessariamente da renda - como o acesso à alimentação e à água, à saúde, à educação, ao transporte, ao saneamento, à informação e à cidadania (NEME et al., 2013).

Em vez de conceituar pobreza como a falta de meios para atingir padrões básicos de bem-estar, pode-se dizer que ela é simplesmente definida como "o não acesso a esses padrões". Dessa maneira, os pobres seriam aqueles que usufruem de um nível de vida, em termos de acesso ao consumo e a serviços, abaixo dos padrões de uma dada sociedade, o que não depende somente da renda de que dispõem, sendo a pobreza, assim, multidimensional (NEME et al., 2013).

O Brasil possui os Programas de Transferência Condicionada de Renda, dos quais se destaca o Programa Bolsa Família (PBF). Lançado em 2003, no governo do Presidente Luís Inácio Lula da Silva, o PBF unificou programas já existentes, tais como o Bolsa Escola e Vale-gás, e fez parte de um programa de governo maior denominado Fome Zero (BRASIL, 2018). Assim sendo, pontua-se que o Bolsa Família se consolidou como um dos programas mais importantes no país entre os anos de 2003 a 2016, principalmente por reduzir os níveis de pobreza do país, permitindo que famílias acessem os serviços básicos e fundamentais, tais como a continuidade dos estudos, os serviços básicos de saúde, alimentação melhor, por meio das condicionalidades definidas pelo programa às famílias enquadradas nos critérios de elegibilidade.

Segundo Tapajós et al. (2010, p.76), "durante o período de 2004 a 2010, foram contratadas dez avaliações com foco prioritário no PBF", o que se justifica "pela convicção da importância de se aferir resultados de um programa de transferência de renda de tamanha magnitude" (TAPAJÓs et al., 2010, p.77).

Conforme estudo realizado pelo Instituto de Pesquisa Econômica Aplicada (IPEA, 2017), fundação pública federal vinculada ao Ministério do Planejamento, a cada $\mathrm{R} \$ 1,00$ transferido às famílias do programa, o Produto Interno Bruto (PIB) municipal tem um acréscimo de R\$ 1,78.

Tendo em vista os dados, o objetivo do presente estudo é verificar como o PBF influencia nas condições de vida das famílias, por meio da percepção das mulheres beneficiárias que vivem no Assentamento Nova Descoberta, no Município de São Raimundo das Mangabeiras. A pesquisa fundamenta-se teoricamente nas dimensões de desenvolvimento propostas por Amartya Sen (2010). 
Vale destacar que o Bolsa Família, no Município de São Raimundo das Mangabeiras, apresenta fatores relevantes que apontam para uma melhoria no quadro da pobreza no município. Existem indícios, principalmente, de que houve mudança, se comparado a outros anos, como, por exemplo, em 2010, quando a incidência de pobreza no município era "de $61,62 \%$ e o percentual dos que estavam abaixo do nível de pobreza era de 50,66\%" (CORREIA FILHO, 2011). Compreender como a minimização das restrições de acesso aos padrões básicos de bem-estar impacta na vida das beneficiárias em um assentamento rural do município se soma aos estudos existentes e contribui para evidenciar como o PBF se articula com o desenvolvimento de um grupo social, de forma articulada com os pressupostos teóricos de Sen (2010). 0 autor condiciona a ação livre do indivíduo à supressão das restrições de acesso aos padrões básicos de bem-estar.

\section{POLÍTICAS PÚBLICAS PARA REDUÇÃO DAS DESIGUALDADES NO BRASIL}

O campo que permeia as questões sociais no Brasil deve ser percebido de forma peculiar, pois a questão das desigualdades sociais presenciadas no país não reside tão somente na existência de direitos, mas sim, na questão da não materialização deles. Nesse sentido, as políticas públicas no Brasil necessitam ser compreendidas a partir da percepção da realidade do país, e isso implica que se deve ir além dos domínios de métodos e técnicas, alcançando um comprometimento real com as lutas para que haja a universalização dos direitos (SILVA, 2010).

No Brasil, essas lutas ganharam força a partir da década de 1930. Nesse período, as medidas de proteção social passaram a ter mais vigor em termos de políticas públicas; antes, as políticas implementadas eram isoladas e o Estado ainda não tinha legitimado para si nenhuma responsabilidade na garantia dos direitos sociais.

Com o Estado intervencionista, começa a se perceber de forma mais direta a responsabilidade do Estado em garantir políticas públicas, fato que começa a ser perceptível nas Constituições de 1926/1934/1937 em diante. Entretanto, foi somente com a Constituição de 1988, cuja promulgação contou de forma incisiva com a participação dos movimentos sociais, que se atribuiu de forma direta a responsabilidade do Estado em implementar políticas públicas de cunho universalista com vistas à promoção da cidadania. Particularmente, o campo da Política de Assistência Social passou, então, a ter contornos diferenciados, uma vez que foram introduzidos após a CF/88, dispositivo que visa igualdade de direitos (SILVA, 2010).

Para o enfrentamento da pobreza no Brasil, houve ampliação das políticas públicas voltadas para o benefício da previdência, em que se estabeleceu um benefício mínimo da Previdência Social aos trabalhadores urbanos e rurais para um salário mínimo e a extensão da aposentadoria para os trabalhadores rurais. E foi a conquista dessa aposentadoria rural que se constitui, na atualidade, uma das principais políticas de enfrentamento à pobreza (SILVA, 2010).

Ainda na questão evolutiva sobre as medidas de políticas públicas, em junho de 2001, foi criado o Fundo de Combate à Pobreza, que passou a financiar programas de transferência de renda associados à educação e a ações de saneamento. A partir de então, o país ingressou em melhorias de vários âmbitos no tocante à criação de políticas públicas de combate à fome e à pobreza, como: Bolsa Escola, Bolsa Alimentação, Fome Zero e Bolsa Família, programa que, posteriormente, será apresentado. Um grande entusiasta do Programa Fome Zero foi Frei Betto ${ }^{3}$ (BRASIL, 2010).

3 O Frade dominicano Carlos Alberto Libâneo Christo, foi um dos líderes do Fome Zero. Foi assessor especial da presidência e coordenador de mobilização social para o Fome Zero. Em 2004, incomodado com os rumos da política econômica do país, ele se desligou das suas atividades ligadas diretamente ao programa. (BRASIL, 2010). 
Assim, muitos programas criados tiveram como base a eliminação das desigualdades sociais, impressa na sociedade desde a sua gênese, descrita por Souza (2015) como uma herança direta da escravidão que precisa ser combatida. $O$ autor aponta que essa herança é percebida até os dias atuais, apontando que hoje existem os novos escravos, uma nova "ralé" produzida pelo capitalismo.

Para Susini e Cabrera (2010), o desenvolvimento econômico possui relação direta com a distribuição de renda. Já Amartya Sen (2010, p. 16) elucida que, para que possa ocorrer desenvolvimento econômico, é preciso que o indivíduo tenha liberdade.

O desenvolvimento requer que se removam as principais fontes de privação de liberdade: pobreza e tirania, carência de oportunidades econômicas e destituição social sistemática, negligência dos serviços públicos e intolerância ou interferência excessiva de Estados repressivos. A despeito de aumentos sem precedentes na opulência global, o mundo atual nega liberdades elementares a um grande número de pessoas - talvez até mesmo à maioria (SEN, 2010, p. 16).

Desse modo, é possível entender que, para se atestar que houve desenvolvimento econômico, não é suficiente apenas verificar que houve aumento da renda per capita, fazendo-se necessária a verificação de dados de natureza qualitativa, abrangendo toda a estrutura econômica e social de uma região.

Segundo Amartya Sen (2010), o desenvolvimento econômico é visto como um procedimento de ampliação da liberdade que as pessoas possuem, tendo a liberdade não só como um fim, mas também como um meio para o desenvolvimento, sendo seu enfoque o indivíduo que se desenvolve pelas suas próprias escolhas e possui um amplo poder de escolha. Sen (2010) parte da ideia de que as liberdades dos indivíduos são determinadas por saúde, educação e direitos civis, e não pela renda per capita, industrialização, avanço tecnológico ou modernização, como apontam as teorias clássicas do desenvolvimento.

Em vista disso, portanto, a teoria de Amartya Sen (2010) concorda com os propósitos liberais que focam as políticas sobre educação no âmbito estatal, sendo que as políticas públicas voltadas para educação e saúde necessitam ser vistas como essenciais para assegurar a liberdade dos indivíduos. Assim, - Estado deve ficar encarregado da eficiência e da igualdade dos resultados de suas políticas públicas, visando garantir as liberdades individuais (SEN, 2010).

Silva et al. (2015) pontuam que, a partir da década de 1990, tornou-se comum a implantação de programas de Políticas de Transferência de Renda na América Latina, que apresentavam diversos qualificadores que representam elementos comuns, transformando-os em uma espécie de estratégia na proteção social com o objetivo de enfrentar os efeitos dos processos econômicos representados pela elevação nos índices de pobreza, indigência e trabalho precarizado.

Considerando a América Latina e suas particularidades, é possível dizer que a extrema concentração de renda e propriedade, bem como os altos índices de exploração das classes menos favorecidas, vêm contribuindo para a manutenção dos índices de desigualdade presentes nesses países.

Neme et al. (2013) indicam que esses programas surgem com o objetivo de promover a igualdade de oportunidades e desenvolvimento econômico e social. De acordo com o autor, essas iniciativas vêm sendo tomadas por governos de países em desenvolvimento em conjunto com diversas organizações internacionais, no entanto não são uma prerrogativa deles, pois mesmo os países desenvolvidos têm buscado esse tipo de política em sua rede de proteção social.

As políticas sociais acabam por assumir o papel de complementador de uma renda que é adquirida, muitas vezes, em atividades informais, e se apresenta como um meio de amenizar as mazelas sociais determinadas pelas estruturas da economia capitalista, sendo um dos reflexos desse processo a dificuldade 
que os países em desenvolvimento, dentre eles, os pertencentes à América Latina e Caribe, têm de absorver a força de trabalho disponível.

No caso brasileiro, com a criação do Bolsa Família, o governo conseguiu avanços significativos com relação à focalização, corrigindo problemas de programas precedentes. Presente em 5.560 municípios e no Distrito Federal, através da transferência de renda direta às famílias de beneficiários, o PBF tem como objetivos básicos, de acordo com o decreto $\mathrm{n}^{\circ} 5.209$, no seu art $4^{\circ}$ :

I - promover o acesso à rede de serviços públicos, em especial, de saúde, educação e assistência social;il - combater a fome e promover a segurança alimentar e nutricional;III - estimular a emancipação sustentada das famílias que vivem em situação de pobreza e extrema pobreza;IV - combater a pobreza; eV - promover a intersetorialidade, a complementaridade e a sinergia das ações sociais do Poder Público (BRASIL, 2004).

O PBF foi criado com o foco na família. Por isso, permitiu superar a pulverização orçamentária e administrativa que caracterizava os diversos programas de transferência de renda então existentes, ao direcionar as ações para todo o grupo familiar e não mais para cada um de seus integrantes de forma isolada. Um dos mais importantes desafios na integração desses programas foi a construção de um Cadastro Único que fosse operado com procedimentos e regras claras. 0 Cadastro Único de Programas Sociais do Governo Federal (Cadastro Único), a partir de 2005, passou por um extenso esforço de depuração dos dados até então existentes, assim como por um amplo processo de cadastramento de novas famílias, orientado pelas estimativas de população pobre para cada município.

Desde sua criação, o PBF foi objeto de vários estudos, tanto no âmbito acadêmico quanto por pesquisas realizadas pelo próprio setor público. Tapajós et al. (2010) elencam um conjunto de estudos, dos quais destacam-se, por evidenciar os aspectos econômicos: a) Estudo realizado pela Pontifícia Universidade Católica de São Paulo, em 2004, que evidenciou a importância do PBF para os municípios mais pobres da região Nordeste, com percentual de beneficiários de 13\% a 45\%; b) pesquisa do Instituto Pólis, em 2005, que demonstrou que o PBF representava acréscimo de $21 \%$ na renda das famílias beneficiadas, sendo o gasto do benefício com alimentação, material escolar, roupas/calçados e remédios.

Grande parte dos estudos, pela dimensão do programa, possui abrangência nacional. Esta pesquisa objetivou focar em um grupo específico, que consiste em um assentamento rural. 0 recorte foi definido pela fragilidade social da população assentada, considerando o histórico da questão agrária nacional.

Levando-se em conta o objeto desta pesquisa, é relevante conhecer os dois modelos de produção agrícola que se destacam na atual fase do capitalismo: o agronegócio e a agricultura familiar, que reproduzem as desigualdades no ambiente rural.

Wanderley (1996, p. 5) esclarece que o pequeno produtor rural do Brasil "sempre ocupou um lugar secundário e subalterno na sociedade brasileira". É sob a pressão do latifúndio que o camponês se move de um lugar para outro, servindo para abrir fronteiras, e, nesse ponto, a autora adverte, "seja como um lugar de refúgio e reconstrução, seja como um lugar de desilusão e fracasso, a fronteira é o lugar da utopia" (WANDERLEY, 1996, p. 12). Para enfrentar essas desigualdades no acesso à terra, uma das medidas do estado é a constituição de assentamento rural, compreendido como "conjunto de unidades agrícolas independentes entre si, instaladas pelo INCRA, onde originalmente existia um imóvel rural que pertencia a um único proprietário" (INSTITUTO NACIONAL DE COLONIZAÇÃO E REFORMA AGRÁRIA, 2020), foco deste estudo. 


\section{METODOLOGIA DA PESQUISA}

Este estudo se caracteriza como descritivo, de abordagem qualitativa, utilizando-se de um roteiro de entrevista para coleta de dados, além de análise documental no Centro de Referência Social de Assistência Social (CRAS) do município de São Raimundo das Mangabeiras - MA e do PDA (Plano de Desenvolvimento Agrário do Assentamento Nova Descoberta).

A pesquisa foi desenvolvida no Assentamento Nova Descoberta, localizado nas mediações da BR 230, na cidade de São Raimundo das Mangabeiras, no Estado do Maranhão. 0 referido município está inserido na Mesorregião Sul Maranhense, dentro da Microrregião da Chapada das Mangabeiras. Limita-se, ao Norte, com os municípios de Mirador e Formosa da Serra Negra; ao Sul, com os municípios de Balsas e Sambaíba; a Leste, com o município de Sambaíba e, a Oeste, com o município de Fortaleza dos Nogueiras.

O município abrange uma área de $3.521,5 \mathrm{~km}^{2}$, com uma população de, aproximadamente, 18.680 habitantes, com densidade demográfica de 4,96 habitantes $/ \mathrm{km}^{2}$ (IBGE, 2010). A pecuária, o extrativismo vegetal, a lavoura temporária, a lavoura permanente, as transferências governamentais, o setor empresarial com 277 unidades atuantes e o trabalho informal são as principais fontes de recursos para o município (CORREIA, 2011).

O histórico de trabalho do Assentamento Nova Descoberta provém de longa data, ligado, principalmente, à luta pela terra. São, atualmente, 15 casas com 14 famílias que manejam seus lotes e que fazem a gestão e tomada de decisão compartilhada, ou seja, é uma experiência de posse coletiva que ganha muita importância, por se tratar de uma região onde o avanço da soja tem sido "facilitado" pela compra de terras de agricultores familiares isolados.

O objeto deste trabalho focou nas famílias que são beneficiárias do Programa Bolsa Família, que, atualmente, são cinco, apesar de ser retratado um perfil geral de toda a comunidade.

O Assentamento limita-se, ao norte, com o riacho Corrente; ao sul, com terras de Candido Costa Araújo e Manoel Artur da Costa e Silva; a oeste, com terras de Demerval Ribeiro Dias e, a leste, com terras da CCAMA, da COOPEVIDA e de Francisco Sales de Moraes. No que se refere aos limites municipais, o imóvel está situado a 40 km em relação à sede do município de São Raimundo das Mangabeiras (DANTAS et al., 2010).

O acesso ao assentamento se dá através da BR-230, partindo da cidade de São Raimundo das Mangabeiras em direção a Balsas. Após $36 \mathrm{~km}$, chega-se ao povoado Vale Verde, e, após mais $2 \mathrm{~km}$, entra-se à direita e percorre-se mais $4 \mathrm{~km}$ por uma estrada carroçável, chegando-se à agrovila do assentamento. A BR-230 está em boas condições de tráfego no trecho entre a sede do município e o assentamento, com exceção de dois trechos com lombadas e buracos. Nesse trecho, há pequena quantidade de acostamento e falta sinalização em partes da pista. Já a estrada carroçável que leva ao assentamento, apesar de possibilitar o tráfego, no inverno, apresenta trechos de alagamento, o que dificulta o trânsito de automóveis.

Esta pesquisa seguiu o percurso sugerido por Pimentel (2001), que descreve as pesquisas documentais como o tratamento metodológico realizado a partir de documentos. Foram consideradas publicações oficiais e documentos internos do CRAS de São Raimundo das Mangabeiras - MA, que será considerado também cenário deste estudo, bem como livros, artigos e reportagens sobre o assunto. Trata-se de uma pesquisa capaz de ampliar a visão do pesquisador, para que se consiga chegar a uma opinião comum, como bem afirma Cellard (2008, p. 295): 
[...] o documento escrito constitui uma fonte extremamente preciosa para todo pesquisador nas ciências sociais. Ele é, evidentemente, insubstituível em qualquer reconstituição referente a um passado relativamente distante, pois não é raro que ele represente a quase totalidade dos vestígios da atividade humana em determinadas épocas. Além disso, muito frequentemente, ele permanece como o único testemunho de atividades particulares ocorridas num passado recente.

Em uma segunda etapa, foi realizada pesquisa de campo, com roteiro de entrevista elaborado especificamente para esta pesquisa e aplicado com beneficiárias do Programa Bolsa Família, com vistas a verificar as condições socioeconômicas e fazer análise de conteúdo para que, a partir dos resultados encontrados, fosse possível analisar a consequente influência do PBF no desenvolvimento local. A pesquisa foi submetida e aprovada em Comitê de Ética em Pesquisa, em 20 de março de 2019 (CAAE 09016319.8.0000.5501).

\section{RESULTADOS E DISCUSSÃo}

No município de São Raimundo das Mangabeiras, foi constituído um grupo de 30 famílias, sendo que 20 famílias residiam na sede do município e 10, no povoado Vale Verde. A coordenação dos Grupos de Produção Base (GPB) era feita localmente pelo Sindicato dos Trabalhadores e Trabalhadoras Rurais (STTR) de São Raimundo das Mangabeiras, que, na época, tinha como presidente o Sr. Joaquim Alves da Silva, mais conhecido como Joaquim das Mangabeiras, um grande líder sindical do sul do Maranhão. A organização produtiva, a partir dos GPB, contemplava capacitação técnica e político-organizativa das famílias agricultoras, como também visava conquistar terra para assentar famílias e financiamento para produção agroextrativista. (DANTAS et al., 2010).

Foi questionado, junto às famílias, como ocorreu a aquisição do território em que residem. Elas apontam que a aquisição se deu por meio da ocupação do território, sendo o processo de ocupação realizado por 30 famílias que vieram do Vale Verde e da sede do município. Inicialmente foi feita a divisão de uma área para o plantio coletivo de arroz, feijão e mandioca. Nos anos seguintes, foi realizada a construção das primeiras casas para as famílias ocupantes, a construção da cerca de proteção às roças e de uma sede para a associação de moradores que havia sido criada a algum tempo antes. (DANTAS et al., 2010)

O Assentamento Nova Descoberta tem como entidade representativa a Associação dos Agricultores da Comunidade Nova Descoberta, inscrita no CNPJ: 12.080.677/0001-68, após a fundação, em 1990, que aconteceu bem antes do local ter se transformado em assentamento de reforma agrária. A AAND é uma sociedade civil sem fins lucrativos com sede no assentamento Nova Descoberta e com comarca em São Raimundo das Mangabeiras, sendo presidida, atualmente, pelo Sr. José Marques da Silva, uma das lideranças entrevistadas.

A referida entidade possui, atualmente, 15 sócios. A direção da AAND se reúne com uma constância bem maior que a maioria das associações dos assentamentos da região, e isso lhe permite ser mais atuante do que qualquer outra. Essas reuniões acontecem todos os primeiros sábados do mês, com a participação efetiva de todas as famílias locais.

No âmbito local, todas as famílias encontram-se organizadas na Associação dos Agricultores da Comunidade Nova Descoberta - AAND, inserida em um contexto organizacional que integra diversas entidades da agricultura familiar do estado maranhense, nos níveis local, regional, estadual e nacional. Essas organizações complementam-se em um esforço de mobilização, organização e fortalecimento da agricultura familiar agroextrativista do cerrado maranhense.

O Assentamento Nova Descoberta possui uma divisão social do trabalho com relativa diferença das comunidades da região. A participação nos fóruns sobre gênero permite que as mulheres locais, mesmo desenvolvendo a chamada "dupla jornada de trabalho", na qual executam as tarefas domésticas - lavar, 
passar, cozinhar, cuidar das crianças - somada ao trabalho da roça, tenham consciência dessa condição e discutam com maridos e filhos para que essa jornada seja mais bem dividida entre todos os membros da família É essa condição que permite que essas mulheres possam participar das organizações sociais citadas no item anterior.

Os homens trabalham no preparo do campo agrícola, plantio, colheita e em outras roças para ganharem diárias. Estão envolvidos, também, nas ações das organizações sociais nas quais fazem parte. Nesse sentido, para o segmento masculino, mesmo havendo uma divisão de trabalho, há um grande respeito ao trabalho feminino, que não é entendido apenas como uma contribuição, mas como uma ação efetiva. As crianças desempenham tarefas de forma moderada, não se caracterizando em trabalho infantil. Nesse aspecto, é importante lembrar que o trabalho da unidade produtiva está baseado na agricultura familiar, e, sendo assim, as crianças habituam-se em participar da colheita e realizam serviços domésticos, tais como: preparar a comida e deixar para os pais na roça, varrer a casa e cuidar dos irmãos menores.

Conforme relato de lideranças, como o de José Marques (presidente da Associação do Assentamento Nova Descoberta), no início do acampamento, quando a primeira vila ainda se localizava às margens do riacho Corrente, havia uma escola multisseriada, na qual lecionava apenas uma professora (trabalhadora rural) que ensinava as primeiras letras às crianças. Depois, a comunidade, na segunda Agrovila, passou a estudar em uma casinha de palha que era, então, de um dos moradores. Posteriormente, as aulas passaram a ocorrer na casa comunitária construída com paredes de adobe (tijolo de barro cru).

Os alunos que terminavam a $4^{\text {a }}$ serie seguiam os estudos no povoado Vale Verde, a uma distância de $6 \mathrm{~km}$ da agrovila do assentamento. 0 meio de transporte dos estudantes, na época, era feito por bicicletas, doadas pela Prefeitura de São Raimundo das Mangabeiras, após muita insistência da comunidade. Entretanto, a escola do povoado Vale Verde só atendia até a $8^{a}$ série do ensino fundamental. Tal fato trouxe sérias consequências na vida escolar da maioria dos jovens do assentamento, que acabavam interrompendo muito cedo os estudos por falta de oportunidades para prosseguir no ensino médio.

Frente a esse grave fato que prejudicava a maioria dos jovens em idade escolar, a Comunidade, com o apoio do STTR do Município de São Raimundo das Mangabeiras, pressionou para que a Prefeitura garantisse transporte escolar. A prefeitura resistiu para disponibilizar o ônibus escolar, pois achava que não tinha esse dever, já que havia doado as bicicletas, mas, após insistência, a prefeitura acabou por garantir o ônibus. Entretanto, o conquistado transporte escolar não era assíduo, o que provocou muitas ausências dos alunos na escola, ocasionando recuperação por excesso de faltas.

A comunidade não possui posto de saúde. 0 acompanhamento rotineiro dos problemas dessa área é realizado localmente por agentes de saúde. Não há atendimento médico no assentamento. Os casos mais graves de algum assentado são encaminhados ao hospital de São Raimundo das Mangabeiras. As doenças mais frequentes são: verminose, gripe, dor na coluna e diarreia, tratadas, em grande parte, recorrendo-se ao uso de remédios caseiros à base de plantas medicinais, nos casos menos graves. A vacinação das crianças é realizada por meio de campanhas e no hospital de São Raimundo das Mangabeiras, a 36 km.

A água utilizada para o consumo humano é da caixa d'água advinda do poço artesiano, sem receber nenhum tipo de tratamento prévio, apenas a filtragem pelo filtro de barro ou outro meio de filtração escoIhido pelas famílias.

As casas do assentamento possuem banheiros e fossas sépticas utilizadas por todas as famílias. Quanto ao destino do lixo doméstico, para algumas famílias, é feito por incineração em um barreiro. 
As atividades agropecuárias se destacam no Assentamento Nova Descoberta, principalmente pela notada e reconhecida ação ambiental desenvolvida pelas famílias locais, preservando, conservando e produzindo de forma sustentável e solidária, construindo uma rede produtiva com tecnologias apropriadas à agricultura familiar maranhense, a exemplo do roço seletivo, cultivo de espécies vegetais e criação de animais diversificados.

Uma das entrevistadas, identificada como "Entrevistada F", recebeu o Bolsa Família de 2012 a 2016 e, por melhora de sua renda, pôde dispensá-lo. Foi entrevistada por ser uma importante liderança dentro da comunidade. Ela relata:

Nossas atividades aqui são diversificadas, trabalhamos com polpa, claro com agricultura, feijão, arroz, vende na feira e deposita também na cooperativa. Vendemos também na porta, temos um grupo formado recentemente de produtos de higiene e limpeza, temos amaciante, sabonete também. [sic] (ENTREVISTADA F, 2019)

Nota-se, pela fala dos entrevistados, que as famílias assentadas desenvolvem agricultura de base familiar e, para subsistência, essa forma de cultivo compõe a renda familiar, como será analisado a seguir, apesar de não declararem o lucro com as vendas. Outras atividades também são desenvolvidas na comunidade, mas as atividades básicas são baseadas no cultivo de caju (com a própria produção de cajuína), culturas anuais (mandioca, feijão, milho, gergelim, fava e arroz) e criação de pequenos animais (galinhas caipiras, por exemplo).

Para caracterização geral do Assentamento Nova Descoberta, será utilizado um roteiro de entrevistas para nortear a discussão dos resultados relacionados especificamente às beneficiárias do PBF. Ressalta-se que, atualmente, existem 5 beneficiárias do PBF no Assentamento.

A faixa etária das beneficiárias varia entre 29 a 52 anos de idade. Dessas, uma tem união estável e quatro são legalmente casadas. Das cinco, uma tem ensino superior e cursou pedagogia. As outras beneficiárias possuem apenas o ensino fundamental incompleto. Quatro são lavradoras e uma é diarista, mas todas têm no PBF sua única fonte de renda fixa. 0 tempo que recebem esse benefício varia entre 6 a 16 anos. Todas tomaram ciência sobre a existência desse programa pelas Secretaria de Assistência Social, Centro de Referência de Assistência Social (CRAS), Associação dos Moradores do Assentamento ou pela Secretaria de Educação.

Quanto ao valor que cada uma recebe (varia de $\mathrm{R} \$ 90,00$ a $\mathrm{R} \$ 340,00$ ), relatam que é um complemento importante em suas rendas. Todas as beneficiárias entrevistadas têm o PBF como único programa de governo recebido e todas declaram que fizeram e fazem cursos profissionalizantes, quando surgem oportunidades.

Quanto à composição familiar, mais precisamente, quanto ao número de pessoas na família, a maior parte das famílias tem mais de 4 membros, apenas uma tem 3.

Afere-se, da fala das entrevistadas, que as famílias adentram o assentamento com a perspectiva de mudança de vida.

[...] eu sou maranhense, daqui mesmo de Mangabeiras, e fui pro Goiás tentar melhorar de vida, lá conheci meu marido que também não era de lá, é da Bahia e quando vim de Luziânia em 2013, vim a todo vapor tentando reconstruir minha vida aqui porque lá a violência era muito grande, até hoje meus filhos são traumatizados por isso, chegando aqui nessa calmaria eu encontrei abrigo, aqui é onde minha mãe mora, eu precisava vim pra cuidar dela também, pra tirar meus filhos daquele lugar, pra mostrar pra eles que a gente pode viver da terra, que precisamos do básico para sobreviver, veio só eu e eles, depois que meu marido veio, viemos mesmo só com a roupa do corpo (...) [sic] (ENTREVISTADA C, 2019)

Outra entrevistada, identificada como "Entrevistada A", saiu do município de Buriticupu - MA e encontrou no Assentamento uma possibilidade de reconstruir sua vida. Para ela, o PBF foi fundamental nesse processo. 
Na época em que sai da cidade pra vir pra cá muito me questionaram...mas eu acreditei que por ser um local que está em fase crescimento, eu vim... aos poucos fui percebendo que mesmo com dificuldades a gente pode sim melhorar de vida. Tinha dias que não tinha nem o que comer direito, o dinheiro que conseguia era insuficiente não dava pra quase nada. Assim que consegui o Bolsa Família, eu pude me firmar melhor pois o benefício me deu um ar pra respirar sabe, foi uma ajuda...aliás é juma ajuda e tanto, aos poucos consegui refazer minha vida, com a ajuda do benefício pude voltar a estudar e hoje graças a essa ajuda sou formada em pedagogia. [sic]. (ENTREVISTADA A, 2019)

O que se verifica é que, com o recurso advindo do PBF ela pôde, por exemplo, se graduar em Pedagogia. O valor que ela recebe do programa hoje não só ajuda nas despesas, como alimentação e transporte, como oportunizou que ela fizesse um curso superior.

As famílias foram questionadas sobre as suas origens, antes de morar no assentamento. A relevância dessa questão repousa no fato de que assim se percebe o quanto o lugar buscado para firmar moradia pode favorecer a qualidade de vida das famílias, uma vez que, no lugar de origem, não havia essa perspectiva, seja por recursos escassos ou ausência de oportunidade do governo em proporcionar o bem-estar social a seus cidadãos.

Sobre a possibilidade de mudança de vida após o recebimento do benefício do PBF, todas as beneficiárias ressaltaram que o PBF trouxe uma mudança significativa na condição de vida da família. 0 programa auxiliou na aquisição de bens materiais que lhes deram certo conforto. Isso se reflete também na questão alimentar, que, pelos relatos, melhorou bastante. Muitas utilizaram e ainda utilizam parte do dinheiro que recebem para fazerem cursos profissionalizantes e de capacitação, pois têm consciência de que esse recurso irá acabar um dia e se preocupam em garantir uma outra fonte de renda. Também atribuem ao PBF a possibilidade de proporcionarem aos filhos melhorias em seu processo educacional.

Dentre as falas que ressaltam os benefícios do PBF às famílias, seguem os relatos que melhor definem tal situação:

Segundo a entrevistada A, o PBF possibilita um "chão firme para pisar", dá alicerce para poder construir sonhos.

Tudo o que conquistei na minha vida foi à base de muito suor e sacrifício, e muitas vezes o que conseguia dava somente para comprar alimentos e mal dava pra pagar as contas, não sobrava nada, pra melhoria da vida, nada...nadinha... nossa, depois do bolsa família eu pude voltar a sonhar em conquistar as coisas, ter condições até pra comprar um guarda-roupa, nossas roupas viviam amontoada numa caixa de papelão, eu sei que muitos falam que viver de bolsa família é fácil, mas, não...nós não vivemos de bolsa família, esse benefício nos ajuda, nos dá um chão firme pra pisar e mesmo que as coisas não andem bem, o beneficio está lá certinho todo final do mês pra nos fortalecer nessa vida dura. [sic] (ENTREVISTADA A, 2019)

\section{A Entrevistada C destaca:}

[...] melhorou, a gente podia fazer compromisso, porque quando se trabalha como lavradora não tem aquele todo mês certinho, é só o que vai produzir. Com ele (BF) eu podia fazer um compromisso, como por exemplo comprar os materiais dos meninos, podia comprar roupa pra pagar com o cartão porque eu sabia que ia ter aquele ali. As minhas coisas de casa quando cheguei aqui pagava só com o BF (guarda-roupa, cama) porque quando me mudei trouxe só as crianças. Quando consegui aqui (BF), que foi bem rápido, a loja financiava e eu pagava com o BF. Eu nunca parei de correr atrás das coisas e viver só do BF, mas ele me ajuda muito até hoje. Eu compro financiado, faço as prestações até o valor de R\$70,00 reais e o que sobra é para comprar outras coisas. [sic] (ENTREVISTADA C, 2019)

\section{E destaca-se, também, o relato da Entrevistada B:}

[...] comprei um tanquinho de lavar roupa, estou pagando as prestações, mas antes era com os meninos na escola mesmo, em roupas, calçados, material escolar, computador para eles. Fui até criticada porque comprei um computador pra eles, mas o BF é pra eles mesmo. [sic] (ENTREVISTADA B, 2019) 
A Entrevistada E afirma:

[...] eu sabia que tinha todo mês, tirava aquele pouquinho para não faltar o dos meninos, para eles comprar uma merendinha na escola, comprar uma roupa, uma coisa no colégio que precisasse, eu nunca deixei faltar, assim, isso aí eu sei que era deles, fora coisa para eles comer mesmo, foi só essas coisas mesmo. 0 que eu adquiri foi, assim, além das coisas deles (filhos) que eu comprava, material, eu comprei duas camas, para cada um deles, [...] comprei um sofá, tá bem aqui, aí eu comprava e fazia as prestações bem miudinha, fazia prestação de cinquenta até cem reais. [sic] (ENTREVISTADA E, 2019)

E, por fim, a Entrevistada D aponta uma visão bem peculiar sobre o PBF, afırmando que:

foi difícil eu conseguir o bolsa família, há uma série de requisitos que precisam ser conferidos...olha fazia uns 10 anos que eu vinha lutando com uma geladeira velha, um problema que me prejudicava demais, pois, a comida estragava, a água ficava quente, fora a conta de luz que vinha ALTA por que a porta não fechava direito, depois do Bolsa Família pude ter paz e sossego...olha tinha noites que eu não dormia preocupada por que imagina o dinheiro que pegava pra comprar comida a geladeira estragava...depois que consegui o benefício até dormi melhor, pois pude concretizar a compra de uma geladeira nova e acabar com esse problema de vez. [sic] (ENTREVISTADA D, 2019)

O Bolsa Família é um Programa de Transferência de Renda que garante as famílias beneficiárias o acesso ao recurso financeiro, possibilitando, dessa forma, uma melhoria na condição de vida. Portanto, nos depoimentos coletados com as entrevistadas acerca da importância do Bolsa Família em suas vidas, todas afirmaram que é um benefício de extrema relevância, porque favorece uma condição de vida melhor, possibilitando que tenham certo poder de compra, ou seja, estimulando o consumo, embora perceba-se, nos depoimentos, que esse programa não tenha resolvido totalmente a situação, mas, de certa forma, tem minimizado sua condição de pobreza ou de extrema pobreza.

Em relação à pergunta realizada sobre a aplicação dada com o dinheiro recebido do $\mathrm{PBF}$, em todas as respostas constam os estudos, a aquisição de utensílios domésticos e a melhoria na alimentação como conquistas advindas com a ajuda do PBF.

Como o PBF é a única fonte de renda fixa que recebem, é com ele que conseguem ter crédito no comércio local para realizar suas compras a prazo. Muitos utensílios presentes nas suas residências foram adquiridos dessa forma, como já foi visto em falas anteriores. Entre os itens mais citados, destacam-se a aquisição de roupas, calçados, material escolar, utensílios domésticos e alimentação.

Todas relatam que, antes, conseguiam realizar essas compras básicas da casa (tais como comida, artigos de higiene e limpeza) com muita dificuldade e que, hoje, o PBF também é utilizado para suprir essas necessidades básicas de suas famílias. Assim, a partir das respostas dadas pelas beneficiárias do PBF do Assentamento Nova Descoberta, infere-se, então, que tal programa ajudou as famílias a melhorarem as condições materiais de suas residências.

As entrevistas mostraram que há um entendimento por parte das beneficiárias de que os recursos do PBF podem ser utilizados para vários fins. As entrevistadas compartilham a ideia de que os recursos do Programa Bolsa Família são destinados à compra de alimentos e de subsídios para a manutenção das crianças na escola e da própria família, principalmente, no quesito alimentação.

Antes do PBF, havia o programa Fome Zero, cujo objetivo era erradicar a fome e assegurar o direito à alimentação da família. 0 pilar do programa residia no fato de que todas as pessoas deveriam ter acesso direto e diário a alimentos de qualidade. O programa envolvia três eixos: 1) ampliação da demanda efetiva de alimentos; 2) barateamento do preço dos alimentos e, 3) programas emergenciais para atender à parcela da população excluída do mercado. Assim, o Programa erradicou a pobreza extrema, que era de $9,79 \%$, em 2012 , e no ano de 2017 , caiu para $3,56 \%$. 
Contudo, mesmo com tanta melhoria no tocante à erradicação da pobreza, o programa em seu formato original foi abandonado, dando espaço ao Bolsa Família, que passou a vincular muitos outros recursos, entre eles, a associação do benefício à frequência escolar das crianças.

Por fim, o PBF se apresenta também como programa que possibilitou maior autonomia das mulheres, pois cabe a elas o recebimento do benefício. Para entender tal situação, basta observar que, geralmente, o Cadastro único tem, preferencialmente, a mulher como responsável pelas informações.

Desse modo o PBF, além de proporcionar autonomia às mulheres, confere a elas a questão da equidade quanto ao gênero. Uma das entrevistadas ressalta a importância da titularidade do cartão do PBF pertencer à mulher, justificando o maior conhecimento pelas mães das necessidades dos filhos e do seu núcleo familiar.

Quanto à pergunta "Você acredita que, após receber o benefício, sua família passou a ter mais oportunidades? De que forma?", a resposta de todas as entrevistadas foi que sim. Novas oportunidades surgiram a partir do acesso a uma educação de qualidade e de cursos de capacitação. Mesmo que a maioria das beneficiárias não tenham conseguido concluir o ensino fundamental, reconhecem melhoria na educação que podem oferecer aos filhos, com a possibilidade de mudança de vida e não de lugar. Todas registram sobre a expectativa de que seus filhos possam aplicar o conhecimento adquirido com os livros na própria comunidade.

Os filhos de 4 beneficiárias já frequentavam a escola antes delas participarem do programa. Essas participantes da pesquisa ressaltaram que, com o dinheiro recebido, puderam comprar o material necessário para que os filhos conseguissem melhorar seus rendimentos escolares. Poder comprar lápis, caderno, bolsas e mesmo um computador para os filhos, como citado acima, ajudou bastante os filhos em seus processos de ensino-aprendizagem. Acreditam que, somente através do acesso a melhores condições educacionais, seus filhos poderão construir uma vida melhor, o que contribui para o investimento na educação deles.

Houve também benefícios em outras áreas. Na saúde, por exemplo, houve uma melhora sensível. Passaram a ter acesso a médicos e a comprar remédios, quando necessário, ou pagar transporte para se deslocar até a sede do município para receber algum atendimento, uma vez que não há posto de saúde dentro do assentamento. O PBF também é usado para garantir o acesso a tratamento de saúde.

Outro item citado foi a preocupação maior com a vacinação das crianças. Quanto à pergunta "A saúde da família melhorou após a inclusão no programa? Por quê?", todas também responderam que sim. Com esse recurso, quando precisam, podem chegar até a cidade para fazer uma consulta ou comprar remédio.

Todas relatam uma vida cheia de grandes dificuldades/necessidades antes de receberem o PBF e que, após o ingresso ao programa, houve uma melhora significativa e que o PBF tem sido um dos promotores dessa mudança.

Quanto à melhoria nas atividades profissionais, as 5 beneficiárias destacam a possibilidade que têm hoje de pagar um curso de capacitação. Uma beneficiária iniciou e concluiu o curso superior de pedagogia só com o dinheiro do PBF. Assim, todas consideram que o PBF possibilita oportunidades de trabalho, uma vez que, com parte desse recurso, é possível se especializar e se capacitar. 


\section{CONSIDERAÇÕES FINAIS}

Considerando o Brasil um país com altos índices de desigualdade social, que inclui má distribuição de renda e escassez de oportunidades de inclusão social, entende-se que os programas de transferência de renda têm se tornado a principal política de enfrentamento à pobreza no país, se consolidando em um sistema de proteção social brasileiro.

Verificou-se que a promulgação da Constituição Federal de 1988 contribuiu efetivamente para a construção no Plano Legal de proteção social brasileiro, responsabilizando o Estado, no que diz respeito à proteção social e concebendo a política social como um direito do cidadão.

No decorrer do desenvolvimento do presente trabalho, notou-se que, com a criação dos Programas de Transferência de Renda na década de 1990, a desigualdade social e a pobreza sofreram uma significativa queda. Embora as políticas de transferência de renda da década de 1990 tenham tido sucesso no enfrentamento à pobreza, o programa que obteve maior impacto foi o Bolsa Família, criado no ano de 2003.

Considerando que as condicionalidades do PBF tenham obtido impacto na educação, é preciso, além de exigir a presença das crianças na escola, que o governo ofereça a elas uma educação melhor, com professores qualificados, materiais escolares e escolas adequadas para sua aprendizagem.

Constatou-se que o Programa Bolsa Família se tornou um programa de ampla cobertura e de grande impacto sobre as condições de vida das famílias beneficiárias, garantindo a elas a construção de uma trajetória de autonomia e cidadania, o que converge com a ampliação das liberdades identificadas como condição para o desenvolvimento por Amartya Sen (2010).

Contatou-se também que a questão agrária, como a maioria dos aspectos sobre a trajetória do desenvolvimento, foi enquadrada como uma problemática nacional sobre um país em pleno desenvolvimento. 0 que se verifica é que os atuais processos de globalização promovem a questão agrária de maneira nova e desafiadora. A chave para a mudança é que o assentamento, dentro da perspectiva capitalista, tenha suas ações consubstanciadas com um processo político livre e democrático e, portanto, haja uma nova dinâmica para esses assentamentos dentro do sistema estatal que se encontra em evolução.

Nesse cenário, o PBF, por meio da transferência de renda e proteção social, possibilitou o alimento na mesa de muitos assentados e, além disso, possibilitou também mudanças significativa nos ajustes econômicos das famílias beneficiadas, que passaram a ter reconhecimento em linhas de crédito. Cabe ressaltar que isso também permitiu um crescimento econômico na localidade, pois algumas famílias passaram a plantar e comercializar alguns dos alimentos na própria localidade.

Enfım, existe uma lacuna que não ainda consegue ser preenchida. Se o governo concede a terra, a produção existe, e as famílias conseguem manter o alimento para além de sua subsistência, podendo vendê-lo para complementar a renda, por outro lado, o governo impõe obstáculos quando não incentiva o pequeno agricultor. Por mais que exista linhas de crédito, nem sempre as famílias alcançam esse crédito e, quando conseguem, as condições para o pagamento não condizem com as suas realidades.

Assim, entende-se que, no assentamento Nova Descoberta, por mais que se tenha apresentado sinais de evolução econômica, muitas famílias ainda necessitam do PBF. Em linhas gerais, conclui-se que, nesse assentamento, o Programa Bolsa Família trouxe possibilidades de evolução econômica e social para localidade, mas, por enquanto, se verificou que muitas famílias ainda não estão aptas a deixar de receber esse benefício, o que significa que elas ainda não conseguiram eliminar grande parte das restrições sociais para o exercício pleno de suas escolhas. 


\section{REFERÊNCIAS}

BRASIL. Bolsa Família e Cadastro Único no seu município: São Raimundo das Mangabeiras/MA. Disponível em: http://mds.gov.br/bolsafamilia. Acesso em: 16 de dez.2018.

BRASIL. Decreto 5.209, de 17 de setembro de 2004. Regulamenta a Lei no 10.836, de 9 de janeiro de 2004, que cria o Programa Bolsa Família, e dá outras providências. Disponível em: http://www.planalto.gov.br/ ccivil_03/_Ato2004-2006/2004/Decreto/D5209.htm. Acesso em: 25 jun. 2019.

BRASIL. Fome Zero: Uma História Brasileira Brasil. 3 volumes. 2010. Ministério do Desenvolvimento Social e Combate à Fome. Brasília. Disponível em: https://www.mds.gov.br/webarquivos/publicacao/Fome\%20 Zero\%20Vol1.pdf. Acesso em: 23 ago. 2019.

BRASIL. Guia de Políticas e Programas do Ministério do Desenvolvimento Social e Combate à Fome - MDS. Brasília, DF, 2008.

BRASIL. Lei n. 10.820, de 17 de dezembro de 2003. Dispõe sobre a autorização para desconto de prestações em folha de pagamento, e dá outras providências. Disponível em: http://www.planalto.gov.br/ccivil_03/ leis/2003/L10.820.htm. Acesso em: 12 dez. 2018.

BRASIL. Ministério do Desenvolvimento Social. Cartilha do Programa Bolsa Família. Disponível em: https:// www.gov.br/cgu/pt-br/centrais-de-conteudo/publicacoes/controle-social/arquivos/bolsafamilia2012.pdf. Acesso em: 21 ago. 2019.

BRASIL. Plano Brasil sem miséria: Cadernos de resultados 2011/2014. Ministério do Desenvolvimento Social. Brasília: 2015. Disponível em: http://www.mds.gov.br/webarquivos/publicacao/brasil_sem_miseria/ cadernodegraficosbsm-35anos.pdf. Acesso em: 20 jan. 2019.

BRASIL. Presidência da República. Lei 10.836, de 9 de janeiro de 2004. Instituem o Programa Bolsa Família, 2004.

CORREIA FILHO, Francisco Lages et al. Projeto cadastro de fontes de abastecimento por água subterrânea: estado do Maranhão, relatório diagnóstico do município de São Raimundo das Mangabeiras. Maranhão: CPRM, 2011. Disponível em: http://rigeo.cprm.gov.br/xmlui/bitstream/handle/doc/15654/rel_sao_raimundo_ mang.pdf?sequence=1. Acesso em: 15 out. 2018.

DANTAS, Anthony Nelson Amaral et al. Plano de Desenvolvimento Agrário do Assentamento Nova Descoberta. São Raimundo das Mangabeiras: Coordenadoria do Agroextrativismo - Cex, 2010.

INSTITUTO NACIONAL DE COLONIZAÇÃO E REFORMA AGRÁRIA. Assentamentos Rurais. 2020. Disponível em: https://antigo.incra.gov.br/pt/assentamentos.html\#: :text=Basicamente\%2C\%200\%20assentamento\%20 rural\%20\%C3\%A9,pertencia\%20a\%20um\%20\%C3\%BAnico\%20propriet\%C3\%A1rio. Acesso em: 26 abr. 2021.

IPEA. Apresentação IPEA. In: CASTRO, Jorge Abrahão de; MODESTO, Lúcia (orgs.) Bolsa família 2003-2010: avanços e desafios. Brasília : Ipea, 2010.

NEME, Flávia et al. Programas de Transferência de Renda: um paradigma em proteção social e combate à pobreza. Simulação das Nações Unidas para Secundaristas. 2013. Disponível em: http://www.sinus.org. br/2013/wp-content/uploads/2013/03/9.-BM-Artigo.pdf. Acesso em: 12 dez. 2018. 
SEN, Amartya Kumar. Desenvolvimento como liberdade. Tradução Laura Teixeira Motta. Revisão técnica Ricardo Doninelli Mendes. São Paulo: Companhia das Letras, 2010.

SILVA. Maria Ozanira da Silva e, et al. Programas de Transferência de Renda na América Latina: contextualização, a pobreza em foco e os significados e controvérsias do potencial das condicionalidades para formação de capital humano e capital social. VII Jornada Internacional de Políticas Públicas. São Luís-MA, 25 a 28 de agosto de 2015.

SILVA. Maria Ozanira da Silva. Pobreza, desigualdade e políticas públicas: caracterizando e problematizando a realidade brasileira. Rev. Katál. Florianópolis v. 13 n. 2 p. 155-163 jul./dez. 2010. Disponível em: http:// www.scielo.br/pdf/rk/v13n2/02.pdf. Acesso em: 15 nov. 2019.

SUSINI, George Marx Coelho Campello; CABRERA, Valéria Cabreira. Algumas considerações sobre desenvolvimento econômico. Revista jurídica eletrônica mensal, n. 155, ano XIX, dez. 2016. Disponível em: http://www.ambitojuridico.com.br/site/index.php?artigo_id=8106\&n_link=revista_artigos_leitura. Acesso em: 08 set. 2018.

TAPAJÓS, Luziele et al. A importância da avaliação no contexto do bolsa família. In: CASTRO, Jorge Abrahão de; MODESTO, Lúcia (orgs.) Bolsa família 2003-2010: avanços e desafios. Brasília: Ipea, 2010.

WANDERLEY, M. N. B. Raízes históricas do campesinato brasileiro. In: XX Encontro Anual da ANPOCS, 1996, Caxambu - MG. Disponível em: http://www.reformaagrariaemdados.org.br/sites/default/files/ Raízes\%20Historicas\%20do\%20Campesinato\%20Brasileiro\%20-\%20Maria\%20de\%20Nazareth\%20Baudel\%20 Wanderley\%20-\%201996.pdf. Acesso em: 2 fev. 2019. 